\title{
Polish Journal of Neurology and Neurosurgery (Neurologia i Neurochirurgia Polska) - update on publication status
}

\author{
Zbigniew K. Wszolek ${ }^{1}$, Łukasz Stolarczyk ${ }^{2}$, Jarosław Sławek ${ }^{3}$ \\ ${ }^{1}$ Co-Editor-in-Chief, Department of Neurology, Mayo Clinic Florida, Jacksonville, Florida, United States \\ ${ }^{2}$ Journal Administrator, Via Medica ${ }^{\mathrm{T \omega}}$, Gdansk, Poland \\ ${ }^{3}$ Co-Editor-in-Chief, Department of Neurology and Psychiatry, Medical University of Gdansk, Gdansk, Poland
}

(Neurol Neurochir Pol 2020; 54 (6): 483-485)

With this issue, we mark three years (the halfway point of our term) of our editorship of the Polish Journal of Neurology and Neurosurgery (PJNNS), published under the Polish title Neurologia i Neurochirurgia Polska.

During this first three years of our editorship, we have implemented a number of changes to the Journal. The most significant ones related to the introduction of new categories of manuscripts such as Invited Editorials and Invited Reviews. However, unsolicited Reviews continue to be a popular manuscript form among our authors. The main categories of our original manuscripts include Research Papers, Short Communications, and Letters to the Editors (on new subjects). We also publish Letters to the Editors as commentaries on previously published articles, and the Response to the Letter to the Editors. These last two categories are becoming more popular among our authors, which is helping to make our Journal more interactive and livelier. We intend to continue this form of publication, and we encourage our Readers to become even more involved. Occasionally, we also publish Guidelines (4 such articles having been published by PJNNS in the last three years). Our final category of manuscripts is Technical Notes. We introduced this mainly to address the needs of our neurosurgical authors, and this current Issue of the Journal indeed features such a manuscript (see page 585). As outlined in our Editorial Note in the Issue of 5/2020, in 2021 we plan to add to the Journal a new feature, in the form of a 'Leading Topic' [1]. Later in the year, we also plan to add to the Research Papers the option for authors to add graphic abstracts to their manuscripts. Such illustrations of the main article message will enhance its focus, and we hope boost its downloads and readership.

Over the last three years, in all manuscript categories, PJNNS has published a total of 292 items, comprising 125 items in 2018, 76 in 2019, and 91 this year (Fig. 1A). The majority of manuscripts, 235 to be precise, were on neurological topics (usually submitted by neurologists), 45 were on neurosurgical topics, usually submitted by neurosurgeons, and 12 were on other topics (Fig. 1B). Research Papers constitute the largest segment of published manuscripts over the last three years, with a total of 151 items. Reviews are the second most frequently submitted category, with 52 of them published in these three years (of which 10 were Invited Reviews). Other manuscript types included 28 Letters to the Editors, 24 Invited Editorials (this category includes Editorial Notes written by the editors), 21 Case Reports (N.B. this category was discontinued in 2018), 10 Short Communications, and, as stated above, 4 Guidelines (Fig. 1C).

The ten most cited papers in the research category that includes Research Papers, Short Communications, and Letters to the Editors (on new subjects) from the last three-year collection of manuscripts published in PJNNS are listed in Table 1. Four of these 10 deal with different subjects related to Parkinson's disease, and three of them are on vascular/ stroke topics. Eighty percent of these articles are written by neurologists, and this is in keeping with the overall number of accepted papers in this three-year period ( $80 \%$ of accepted papers being written by neurologists). Seven of the articles were written by foreign authors and three by Polish authors. Interestingly, in this group of 10 most cited research articles are two Letters to the Editors. Both of these dealt with matters related to the Covid-19 pandemic.

During our first three years as editors of PJNNS, we experienced a change of publisher from Elsevier to Via Medica. We are grateful to the editorial teams from both publishing houses for their assistance in making this change smooth and as easy as possible for our authors and readers. For the next

Address for correspondence: Zbigniew K. Wszolek, Department of Neurology, Mayo Clinic Florida, 4500 San Pablo Rd, Jacksonville, FL 32224, USA, e-mail: wszolek.zbigniew@mayo.edu 


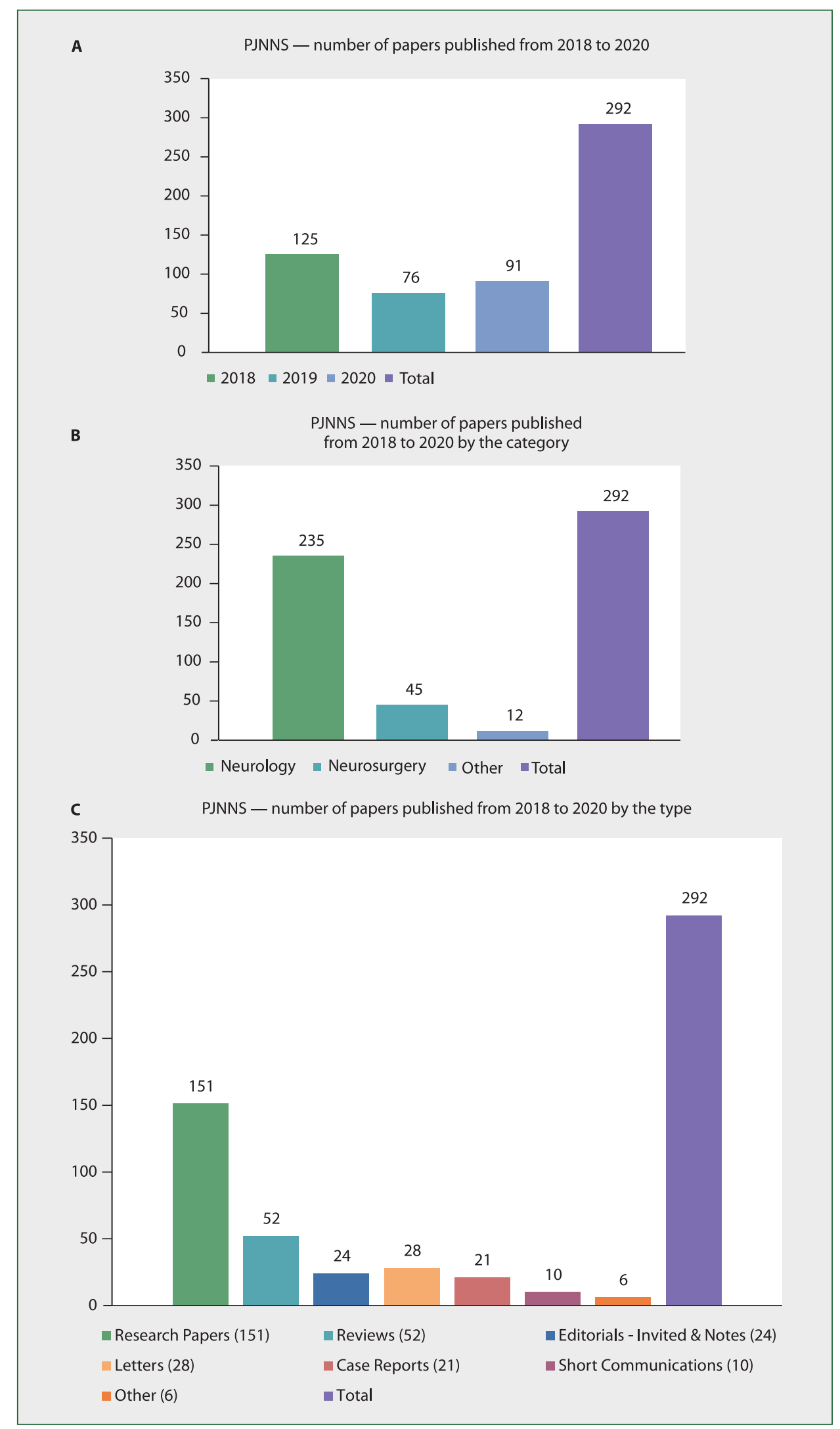

Figure 1. Publication metrics of the Polish Journal of Neurology and Neurosurgery (Neurologia i Neurochirurgia Polska). A, total number of published items over the last three years, from 2018 to 2020 (including this Issue); B, stratification of published items by topic/submitted author speciality (neurology/neurosurgery/other) over the same period; C, depiction of manuscript types published in the same time frame 
Table 1. The 10 most frequently cited manuscripts published by the Polish Journal of Neurology and Neurosurgery (Neurologia i Neurochirurgia Polska) in the last three years (2018-2020)

\begin{tabular}{lcc}
\multicolumn{1}{c}{ Authors } & Document type & Reference \\
\hline $\begin{array}{l}\text { V. Constantinescu, D. Matei, V. Costache, D. Cuciureanu, C. Arsenescu-Georgescu } \\
\text { Asli Bolayir, Seyda Figul Gokce, Burhanettin Cigdem, Hasan Ata Bolayir, Ozlem Kayim Yildiz a,2, } \\
\text { Ertugrul Bolayir, Suat Ahmet Topaktas }\end{array}$ & Research paper & 2 \\
Murad Asiltürk, Anas Abdallah & Research paper & 3 \\
Michalina Malec-Litwinowicz, Andrzej Plewka, Danuta Plewka, Edyta Bogunia, Michał Morek, & Research paper & 4 \\
Andrzej Szczudlik, Michał Szubiga, Monika Rudzińska-Bar & Research paper & 5 \\
Domenico Chirchiglia, Pasquale Chirchiglia, Francesco Signorelli & Research paper & 6 \\
Won Tae Yoon & Research paper & 7 \\
Philip W. Tipton, Zbigniew K. Wszolek & Letter to the Editors* \\
Tomasz Szmuda, Shan Ali, Paweł Słoniewski, NSurg4WL group & Letter to the Editors* \\
Jarosław Dulski, Michał Schinwelski, Agnieszka Konkel, Karol Grabowski, Witold Libionka, Piotr Wąż, & Short communication \\
E.J. Sitek, Jarosław Sławek & & 8 \\
Cahit Kural, Gokce Kaan Atac, Ozkan Tehli, Ilker Solmaz, Caglar Temiz, Irgen Hodaj, Yusuf Izci & Research paper & 10
\end{tabular}

The manuscripts included here were published as Research Papers, Short Communications, or Letters to the Editors (on new subjects). Invited Editorials, Invited Reviews, Reviews, Guidelines, Technical Notes, Case Reports (discontinued in 2018), Letters to the Editors (commenting on previously published articles), and Response to the Letter to the Editors are not included *Only Letters to the Editors on new subjects were considered

three years, we anticipate that Via Medica will continue to serve as our publishing house.

The Journal is in good standing. We receive many more papers for consideration for publication than we could possibly accept. The Journal is gaining increasing international recognition, and continues to be highly popular with Polish neurologists and neurosurgeons. As editors of PJNNS, we hope that our Readership will continue to support the Journal, and that our publishing metrics will continue to grow.

\section{References}

1. Wszołek ZK, Stolarczyk $Ł$, Sławek J. Further publication enhancements discussed during the current Editorial Board meeting of the Polish Journal of Neurology and Neurosurgery (Neurologia i Neurochirurgia Polska). Neurol Neurochir Pol. 2020; 54(5): 361-363, doi: 10.5603/ PJNNS.2020.0085, indexed in Pubmed: 33135150.

2. Constantinescu V, Matei D, Costache V, et al. Linear and nonlinear parameters of heart rate variability in ischemic stroke patients. Neurol Neurochir Pol. 2018; 52(2): 194-206, doi: 10.1016/j. pjnns.2017.10.002, indexed in Pubmed: 29110883.

3. Bolayir A, Gokce SF, Cigdem B, et al. Monocyte/high-density lipoprotein ratio predicts the mortality in ischemic stroke patients. Neurol Neurochir Pol. 2018; 52(2): 150-155, doi: 10.1016/j.pjnns.2017.08.011, indexed in Pubmed: 28864326.

4. Asiltürk M, Abdallah A. Clinical outcomes of multiple aneurysms microsurgical clipping: Evaluation of 90 patients. Neurol Neurochir Pol. 2018; 52(1): 15-24, doi: 10.1016/j.pjnns.2017.09.005, indexed in Pubmed: 28965667.
5. Malec-Litwinowicz M, Plewka A, Plewka D, et al. The relation between plasma $\alpha$-synuclein level and clinical symptoms or signs of Parkinson's disease. Neurol Neurochir Pol. 2018; 52(2): 243-251, doi: 10.1016/j.pjnns.2017.11.009, indexed in Pubmed: 29342421.

6. Chirchiglia D, Chirchiglia P, Signorelli F. Nonsurgical lumbar radiculopathies treated with ultramicronized palmitoylethanolamide (UmPEA): A series of 100 cases. Neurol Neurochir Pol. 2018; 52(1): 44-47, doi: 10.1016/j.pjnns.2017.11.002, indexed in Pubmed: 29157725.

7. Yoon WT. Comparison of dystonia between Parkinson's disease and atypical parkinsonism: The clinical usefulness of dystonia distribution and characteristics in the differential diagnosis of parkinsonism. Neurol Neurochir Pol. 2018; 52(1): 48-53, doi: 10.1016/j. pjnns.2017.11.004, indexed in Pubmed: 29196058.

8. Tipton PW, Wszolek ZK. What can Parkinson's disease teach us about COVID-19? Neurol Neurochir Pol. 2020; 54(2): 204-206, doi: 10.5603/PJNNS.a2020.0039, indexed in Pubmed: 32323862.

9. Szmuda T, Ali S, Słoniewski P, et al. Telemedicine in neurosurgery during the novel coronavirus (COVID-19) pandemic. Neurol Neurochir Pol. 2020; 54(2): 207-208, doi: 10.5603/PJNNS.a2020.0038, indexed in Pubmed: 32319670.

10. Dulski J, Schinwelski M, Konkel A, etal. The impact of subthalamic deep brain stimulation on polysomnographic sleep pattern in patients with Parkinson's disease - Preliminary report. Neurol Neurochir Pol. 2018; 52(4): 514-518, doi: 10.1016/j.pjnns.2018.05.006, indexed in Pubmed: 29887129.

11. Kural C, Atac GK, Tehli O, et al. The evaluation of the effects of steroid treatment on the tumor and peritumoral edema by DWI and MR spectroscopy in brain tumors. Neurol Neurochir Pol. 2018; 52(4): 495-504, doi: 10.1016/j.pjnns.2018.03.002, indexed in Pubmed: 29588064. 